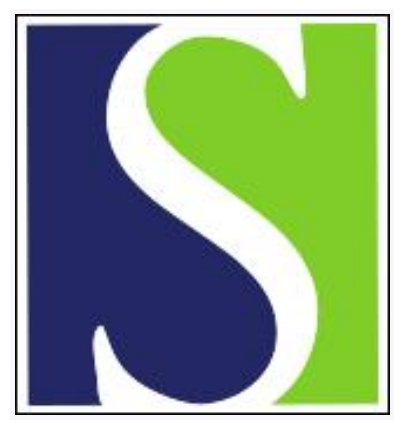

Scand J Work Environ Health 2009;35(5):361-367

https://doi.org/10.5271/sjweh.1344

Published online: 18 Aug 2009, Issue date: 00 Oct 2009

Working shifts and mental health - findings from the British Household Panel Survey (1995-2005)

by Bara AC, Arber $\mathrm{S}$

Affiliation: University of Surrey, Department of Sociology, Guildford, Surrey GU2 7XH, United Kingdom. s.arber@surrey.ac.uk

Refers to the following texts of the Journal: 2001;27(2):97-105 2006;32(3):204-208 2008;34(3):206-212 1996;22(2):133-138

The following articles refer to this text: $2010 ; 36(2): 81-84$;

2010;36(6):458-465; 2011;37(6):551-555; 2013;39(5):515-520; 2015;41(3):268-279; 2015;41(4):356-367; 2015;41(4):413-416; 2018;44(5):512-520; 2019;45(5):458-464

Key terms: anxiety; British Household Panel Survey; depression; gender difference; General Health Questionnaire; Iongitudinal study; mental health; night work; shift; shift work; varied shift pattern; work

This article in PubMed: www.ncbi.nlm.nih.gov/pubmed/19688143 


\title{
Working shifts and mental health - findings from the British Household Panel Survey (1995-2005)
} by Ana-Claudia Bara, PhD, ${ }^{1}$ Sara Arber, $P h D^{1}$

\begin{abstract}
Bara AC, Arber S. Working shifts and mental health - findings from the British Household Panel Survey (19952005). Scand J Work Environ Health. 2009;35(5):361-367.

Objective Our objective was to examine the impact of shift work on mental health at the population level. We expected that this impact would depend on duration of exposure, type of shift work, and gender.

Methods We analyzed longitudinal data (1995-2005) from the British Household Panel Survey. From the 2005 wave, we selected a subsample of people aged 21-73 years who had been followed annually from 1995 to 2005. We used responses in 2005 to the General Health Questionnaire (GHQ, 12-item) and self-reported anxiety/depression as dependent variables. Controlling for age, marital status, education, number of years working in six occupational categories (1995-2005), and baseline mental health, we performed nested logistic regression models to examine the effect of the duration of night work and varied shift patterns on mental health for men and women.
\end{abstract}

Results Undertaking night work for $\geq 4$ years in men was associated with an increased risk of having a GHQ score reflecting mental ill health and reporting anxiety/depression [odds ratios (OR) $2.58,95 \%$ confidence interval $(95 \%$ CI $1.22-5.48$; OR $6.08,95 \%$ CI 2.06-17.92, respectively]. Women were significantly more likely to report anxiety/depression (OR 2.58, 95\% CI 1.53-4.35) and to have a GHQ score reflecting mental ill health (OR 4.17, 95\% CI 1.45-11.98), after working varied shift patterns for 2-3 years, and $\geq 4$ years, respectively.

Conclusions Different types of shift work had a differential impact on mental health, but this impact varied according to gender. Women's mental health was more adversely affected by varied shift patterns, while night work had a greater negative impact on men's mental health.

Key terms anxiety; depression; gender differences; General Health Questionnaire; longitudinal study; night work; shift work; varied shift pattern.

There has been a scarcity of studies on the impact of shift work on mental health. Studies have found an association between shift work and general mental health (1-3), psychological well-being (4-6), irritability/ irritation/strain (7), and severe emotional problems (8). Studies have also shown that shift workers experience depression to different degrees [ie, major depressive disorder $(9,10)$, sub-clinical depression (11)], general malaise including depression and anxiety elements (12), higher levels of burnout (13), more fatigue ( 7,14 , 15), and mental tiredness (16). However, most of these studies were cross-sectional, with limited potential to demonstrate causal relationships. Moreover, some studies have also shown no relationship between shift work and mental health $(17,18)$. Therefore, according to some researchers, the causal relationship between mental health and shift work is still questionable (19), and the importance of using longitudinal data (9) to study the impact of shift work on mental health is emphasized.

Shift work is prevalent in many societies. In 2000, $19.3 \%$ of employees were shift workers in the European Union (15 member states) and $23.0 \%$ were shift workers in the UK (20). Although shift work is stated as an important public health issue in our 24-hour society, most studies have been based on data from single or only a few specific occupational groups, such as healthcare professionals $(16)$ [especially nurses $(1,9)$ or student nurses (5)], garbage workers (21), factory workers (3), and chemical labor unions (7). Additionally, either men $(7)$ or women $(1,5)$ have usually been selected for analysis, but rarely both genders.

We expected a negative impact of shift work on mental health that would vary with the duration of exposure, type of shift work, and gender. Regarding duration,

1 Centre for Research on Ageing and Gender, Department of Sociology, University of Surrey, Guildford, United Kingdom.

Correspondence to: Professor S Arber, University of Surrey, Department of Sociology, Guildford, Surrey GU2 7XH, United Kingdom. [E-mail: s.arber@surrey.ac.uk] 
Scott et al (10) showed (in a pilot study) that undertaking night work for 6-10 years increased the prevalence of depressive disorders over six times compared to undertaking night work for 1-5 years. Another study showed that, measured in 1997, men's and women's poor mental health was related to undertaking shift work in 1993 (11). Therefore, we expected a long term negative impact and that exposure to shift work for a greater number of years would have (more) adversely affected mental health.

Men and women have different gender roles in families and society more generally, and, consequently, undertaking different types of shift work may have a differential impact on men's and women's mental health. However, there has been a scarcity of studies addressing the differential impact of shift work on men and women. Furthermore, most clinical research has focused only on men, thus there has been a lack of evidence to support hypotheses on gender differences. Based on evidence from Shields' research (22), in our study, we expected that women would be (more) adversely affected than men by irregular working hours. Shields showed that men working irregular shifts had a relatively high sense of mastery, while women reported adverse effects in terms of high personal stress.

With respect to night work, studies on (mostly) men (10) and healthcare workers have shown a negative impact of night work on mental health [ie, leading to mental tiredness (16) or fatigue (23)] and psychological well-being (5). There has been a lack of papers addressing gender differences in the impact of night work on mental health, thus we cannot hypothesize in this respect. However, research has shown that women feel less sleepy compared to men during consecutive night shifts, so this may point towards women adapting better to night work (24). Moreover, studies on nurses have shown that they are less adversely affected by night work, compared to working other shift patterns (25). Therefore, although these studies were not carried out in the general population, we expected that men's mental health would be (more) adversely affected by night work than by working varied shift patterns, whereas women's mental health would be more adversely affected by working varied shifts.

Shift workers have often been considered as a selfselected population $(7,19)$. Some authors argued that shift workers may have pre-existing mental problems (19). In contrast, other authors considered shift workers to be healthier than the general population, because of the process of selection into shift work ("healthy worker effect") (26). There is also a selection out of shift work ("healthy shift worker survivor effect"). Some recent studies have shown no differences in illnesses or socio-demographic characteristics between future day and shift workers (27), or between shift or day workers leaving their work due to illness (28). However, these findings are limited to healthcare workers and cardiovascular disease, and cannot be extrapolated to a large range of occupations in a general working population and/or to mental health problems. Furthermore, it has been widely acknowledged that studying the impact of shift work on mental health has been a methodological challenge due to self-selection effects (26). Therefore, our methodological approach was to control for preexisting mental health status.

Studies have shown that the determinants of mental health include: age $(2,29)$, gender $(22)$, marital status (21, 29), lifestyle, job status (29), and job type (18). Additionally, socioeconomic status influences mental health, especially education and employment status (30). However, a study on the first eight waves (1991-1998) of the British Household Panel Survey (BHPS) found that education and income had no impact on self-reported mental health (29).

The aim of our study was to address the relationship between mental health and shift work, examining the impact of working nights or varied shift patterns on the mental health of British men and women. We examined this relationship for men and women controlling for other confounding factors, such as age, marital status, education, employment duration in six occupational categories, and baseline mental health.

\section{Methods}

We analyzed longitudinal data from the BHPS, a nationally representative sample of private households in Britain. We selected, from the 2005 wave, a subsample of people aged 21-73 years who had been followed annually from 1995 to 2005 . The response rate ranged from $64.9 \%$ (wave 2003) to $77.3 \%$ (wave 1995) of eligible respondents from the first wave in 1991 (31). Our sample was restricted to those who had worked for at least one year between 1995 and 2005 (4549 men and 5216 women). Variables were constructed to measure, respectively, the number of years working nightshifts and varied shift patterns between 1995 and 2005. The relevant BHPS question asked: "Which of the categories on this card best describes the times of day you usually work?" The answers were the following: "mornings only", "afternoons only", "during the day", "evenings only", "at night", "both lunchtime and evenings", "other times of day", "rotating shifts", "varies/no usual pattern", "daytime and evenings", and "other" (32). In this paper, we analyzed working "at night" and "varies/no pattern". Additionally, variables were derived to measure the number of the years of employment, between 1995 and 2005, in six occupational categories: (i) professional, 
(ii) managerial and technical, (iii) skilled non-manual, (iv) skilled manual, (v) partly skilled, and (vi) unskilled. We had detailed data on shift work for ten of 11 waves (except 2003), while data for employment in the six occupational categories was available for all 11 waves included in analyses.

The 12-item General Health Questionnaire (GHQ), a screening test for nonorganic, nonpsychosis mental disorders (33), was used in the analyses. With four response categories, the questions included: "Have you recently been able to concentrate on whatever you're doing?" or " ... lost much sleep over worry?" or “ ... been feeling reasonably happy, all things considered?" Valid answers to these 12 items were converted into a derived variable running from 0 (the least distressed) to 12 (the most distressed), by recoding "better than usual" and "same as usual" as 0 , and "less than usual" and "much less than usual" as 1 , and then summing up (34). We dichotomized the summed GHQ scores as $\geq 4$ to reflect mental ill health. Baseline mental health was measured for each individual from the first wave with available information on their GHQ score.

Mental health was also measured via the response in 2005 to the question: "Do you have any of the health problems or disabilities listed on this card?" with the card listing: "anxiety", "depression or bad nerves", and "psychiatric problems". Pre-existing self-reported anxiety/ depression, as measured in the first year with available information, was used as a baseline in the analyses.

Table 1 shows the distributions of the two outcome mental health variables, together with the socio-demographic characteristics of men and women, which are adjusted for in tables 2 and 3. Cases for which there were missing values for a variable were excluded in the analyses and are not shown in table 1 .

Table 1. Socio-demographic characteristics of the respondents. Source: British Household Panel Survey (waves 1995-2005). $\left(\right.$ GCSE $=$ General Certificate of Secondary Education ${ }^{a}, \mathrm{GHQ}=$ General Health Questionnaire)

\begin{tabular}{lrrrrr}
\hline \multirow{2}{*}{ Variables } & \multicolumn{2}{c}{ Men } & & \multicolumn{2}{c}{ Women } \\
\cline { 2 - 3 } \cline { 5 - 6 } & $\mathrm{N}$ & $\%$ & & $\mathrm{~N}$ & $\%$ \\
\hline Age in 2005 & & & & \\
21-25 years & 917 & 9.4 & & 436 & 8.5 \\
26-34 years & 948 & 21.3 & & 1113 & 21.8 \\
35-44 years & 951 & 21.3 & & 1111 & 21.8 \\
45-54 years & 718 & 16.1 & & 849 & 16.6 \\
55-64 years & 253 & 5.7 & & 227 & 4.4 \\
65-73 years & & & & & \\
Marital status in 2005 & 3422 & 75.3 & & 3770 & 72.3 \\
Married/ living as couple & 287 & 6.3 & & 662 & 12.7 \\
Widowed/ divorced/ separated & 838 & 18.4 & & 781 & 15.0 \\
Never married & & & & (continued)
\end{tabular}

Table 1. Continued.

\begin{tabular}{|c|c|c|c|c|}
\hline \multirow[t]{2}{*}{ Variables } & \multicolumn{2}{|c|}{ Men } & \multicolumn{2}{|c|}{ Women } \\
\hline & $\mathrm{N}$ & $\%$ & $\mathrm{~N}$ & $\%$ \\
\hline \multicolumn{5}{|c|}{ Highest educational qualification } \\
\hline Degree or higher & 816 & 19.8 & 9.59 & 19.8 \\
\hline Professional & 1496 & 36.3 & 1574 & 32.6 \\
\hline GCSE A Levels & 527 & 12.8 & 580 & 12.0 \\
\hline GCSE 0 Levels & 617 & 15.0 & 832 & 17.2 \\
\hline Lower qualifications & 247 & 6.0 & 328 & 6.8 \\
\hline Number of qualifications & 419 & 10.2 & 559 & 11.6 \\
\hline \multicolumn{5}{|c|}{ Number of years in professional occupations } \\
\hline 0 years & 387 & 83.7 & 4857 & 93.1 \\
\hline $1-3$ years & 477 & 10.5 & 270 & 5.2 \\
\hline 4-6 years & 163 & 3.6 & 43 & 0.8 \\
\hline $7-11$ years & 102 & 2.2 & 46 & 0.9 \\
\hline \multicolumn{5}{|c|}{ Number of years in managerial \& technical occupations } \\
\hline 0 years & 2310 & 50.8 & 2620 & 50.2 \\
\hline $1-3$ years & 1058 & 23.3 & 1268 & 24.3 \\
\hline $4-6$ years & 591 & 13.0 & 736 & 14.1 \\
\hline $7-11$ years & 590 & 13.0 & 592 & 11.3 \\
\hline \multicolumn{5}{|c|}{ Number of years in skilled non-manual occupations } \\
\hline 0 years & 3245 & 71.3 & 2513 & 48.2 \\
\hline $1-3$ years & 905 & 19.9 & 1290 & 24.7 \\
\hline 4-6 years & 254 & 5.6 & 815 & 15.6 \\
\hline $7-11$ years & 145 & 3.2 & 598 & 11.5 \\
\hline \multicolumn{5}{|c|}{ Number of years in skilled manual occupations } \\
\hline 0 years & 2406 & 52.9 & 4238 & 81.3 \\
\hline $1-3$ years & 1092 & 24.0 & 723 & 13.9 \\
\hline $4-6$ years & 562 & 12.4 & 174 & 3.3 \\
\hline $7-11$ years & 489 & 10.7 & 81 & 1.6 \\
\hline \multicolumn{5}{|c|}{ Number of years in partly skilled occupations } \\
\hline 0 years & 3106 & 68.3 & 3529 & 67.7 \\
\hline $1-3$ years & 1023 & 22.5 & 1184 & 22.7 \\
\hline 4-6 years & 288 & 6.3 & 358 & 6.9 \\
\hline $7-11$ years & 132 & 2.9 & 145 & 2.8 \\
\hline \multicolumn{5}{|c|}{ Number of years in unskilled occupations } \\
\hline 0 years & 4077 & 89.6 & 4670 & 89.5 \\
\hline $1-3$ years & 385 & 8.5 & 407 & 7.8 \\
\hline $4-6$ years & 66 & 1.5 & 86 & 1.6 \\
\hline $7-11$ years & 21 & 0.5 & 74 & 1.0 \\
\hline \multicolumn{5}{|c|}{ Number of waves working nightshifts } \\
\hline 0 years & 4314 & 94.8 & 4983 & 95.5 \\
\hline 1 year & 123 & 2.7 & 108 & 2.1 \\
\hline $2-3$ years & 68 & 1.5 & 77 & 1.5 \\
\hline $4-10$ years & 44 & 1.0 & 48 & 0.9 \\
\hline \multicolumn{5}{|c|}{ Number of waves working varied shifts } \\
\hline 0 years & 4106 & 90.3 & 4685 & 89.8 \\
\hline 1 year & 311 & 6.8 & 372 & 7.1 \\
\hline $2-3$ years & 108 & 2.4 & 143 & 2.7 \\
\hline $4-10$ years & 24 & 0.5 & 16 & 0.3 \\
\hline \multicolumn{5}{|l|}{$\mathrm{GHQ}$-caseness at baseline } \\
\hline Not GHQ case & 3834 & 86.0 & 4014 & 77.5 \\
\hline $\mathrm{GHQ}$ case & 623 & 14.0 & 1168 & 22.5 \\
\hline \multicolumn{5}{|c|}{ Anxiety/depression at baseline } \\
\hline Not mentioned & 4415 & 97.1 & 4875 & 93.5 \\
\hline Anxiety, depression, etc & 128 & 2.8 & 331 & 6.3 \\
\hline \multicolumn{5}{|l|}{ GHQ-caseness in 2005} \\
\hline Not GHQ case & 3498 & 76.9 & 3748 & 71.9 \\
\hline $\mathrm{GHQ}$ case & 614 & 13.5 & 1048 & 20.1 \\
\hline \multicolumn{5}{|l|}{ Anxiety/ depression in 2005} \\
\hline Not mentioned & 4197 & 92.3 & 4519 & 86.6 \\
\hline Anxiety, depression, etc & 168 & 3.7 & 432 & 8.3 \\
\hline
\end{tabular}


Table 2. Odds ratios (OR) of General Health Questionnaire (GHQ)-caseness in men and women by undertaking night/varied shifts, adjusted for age, marital status, education, number of waves working in six occupational categories and GHQ-caseness at baseline. [Source: British Household Panel Survey (waves 1995-2005), 95\% Cl = 95\% confidence interval]

\begin{tabular}{|c|c|c|c|c|c|c|c|c|}
\hline & \multicolumn{4}{|c|}{ Men $(\mathrm{N}=3928)$} & \multicolumn{4}{|c|}{ Women $(\mathrm{N}=4607)$} \\
\hline & \multicolumn{2}{|c|}{ Night shift } & \multicolumn{2}{|c|}{ Varied shift } & \multicolumn{2}{|c|}{ Night shift } & \multicolumn{2}{|c|}{ Varied shift } \\
\hline & $\mathrm{OR}$ & $95 \% \mathrm{Cl}$ & $\mathrm{OR}$ & $95 \% \mathrm{Cl}$ & $\mathrm{OR}$ & $95 \% \mathrm{Cl}$ & $\mathrm{OR}$ & $95 \% \mathrm{Cl}$ \\
\hline \multicolumn{9}{|c|}{ Number of waves working shifts } \\
\hline 0 years & 1.00 & .. & 1.00 &.. & 1.00 & .. & 1.00 & .. \\
\hline 1 year & 0.97 & $0.56-1.71$ & 0.81 & $0.55-1.19$ & 0.93 & $0.56-1.54$ & 1.16 & $0.89-1.53$ \\
\hline $2-3$ years & 1.03 & $0.49-2.16$ & 1.21 & $0.69-2.14$ & 1.03 & $0.58-1.83$ & 1.07 & $0.69-1.66$ \\
\hline $4-10$ years & 2.58 & $1.22-5.48$ & 0.52 & $0.11-2.37$ & 1.06 & $0.49-2.27$ & 4.17 & $1.45-11.98$ \\
\hline Nagelkerke R Square & 0.09 &.. & 0.09 & .. & 0.07 & .. & 0.07 & .. \\
\hline
\end{tabular}

Table 3. Odds ratios $(O R)$ of anxiety/depression in men and women by undertaking night/varied shifts, adjusted for age, marital status, education, number of waves working in six occupational categories, and anxiety/depression at baseline. [Source: British Household Panel Survey (waves 1995-2005), 95\% Cl = 95\% confidence interval]

\begin{tabular}{|c|c|c|c|c|c|c|c|c|}
\hline & \multicolumn{4}{|c|}{ Men $(N=3764)$} & \multicolumn{4}{|c|}{ Women $(\mathrm{N}=4447)$} \\
\hline & \multicolumn{2}{|c|}{ Night shift } & \multicolumn{2}{|c|}{ Varied shift } & \multicolumn{2}{|c|}{ Night shift } & \multicolumn{2}{|c|}{ Varied shift } \\
\hline & $\mathrm{OR}$ & $95 \% \mathrm{Cl}$ & $\mathrm{OR}$ & $95 \% \mathrm{Cl}$ & OR & $95 \% \mathrm{Cl}$ & OR & $95 \% \mathrm{Cl}$ \\
\hline \multicolumn{9}{|c|}{ Number of waves working shifts } \\
\hline 0 years & 1.00 & .. & 1.00 & .. & 1.00 & .. & 1.00 & .. \\
\hline 1 year & 0.46 & $0.13-1.64$ & 1.23 & $0.63-2.41$ & 1.59 & $0.83-3.05$ & 0.85 & $0.54-1.35$ \\
\hline $2-3$ years & 1.83 & $0.61-5.47$ & 0.85 & $0.20-3.67$ & 1.69 & $0.82-3.49$ & 2.58 & $1.53-4.35$ \\
\hline $4-10$ years & 6.08 & $2.06-17.92$ & .. a & .. & 1.69 & $0.60-4.76$ & 3.61 & $0.79-16.51$ \\
\hline Nagelkerke R Square & 0.21 & .. & 0.21 &.. & 0.19 & .. & 0.19 & .. \\
\hline
\end{tabular}

a No men who reported undertaking $\geq 4$ years of varied shift pattern reported anxiety/depression in 2005 .

We used mental ill health (GHQ score $\geq 4)$ and self-reported anxiety/depression in 2005 as dependent variables. We performed nested logistic regression models separately for men and women to examine the effect of the cumulative exposure to years of night work and varied shift patterns on the two measures of mental health (unadjusted in the first model). In the second model, we adjusted for age, marital status, education, and number of years working in six occupational categories (1995-2005). In the third model, we added baseline GHQ-caseness or baseline anxiety/ depression.

Only data from the fully adjusted model (ie, model 3 ) are presented in tables 2 and 3. However, we discuss the first and the second model in the text. Additionally, we performed logistic regression on the sample with both men and women, including an interaction term for shift work-by-gender, in order to test whether there was an interaction between gender and shift work. The analyses were performed with SPSS 15 (SPSS Inc, Chicago, IL, USA).

\section{Results}

According to the unadjusted model (model 1), undertaking night work in men and varied shift pattern in women was associated with an increased risk of being a GHQ case (results not shown here). When controlling for age, marital status, education, and duration of working in six occupational categories, undertaking night work for $\geq 4$ years in men and varied shifts in women remained strongly associated with an increased risk of being a GHQ case (model 2). In both genders, controlling also for baseline GHQ-caseness did not alter this association. This is shown in table 2, which presents the results of the fully adjusted model (model 3) performed separately for men and women.

Similar results were found after performing a logistic regression of the duration of shift work on anxiety/depression. The association between reporting anxiety/depression and duration of shift work in the fully adjusted model is presented in table 3 . 
Our findings demonstrated the differences between the ways in which these two types of shift work, as well as various durations of exposure, affect men's and women's mental health. Men were significantly more likely to be a GHQ case and report anxiety/depression [odds ratio (OR) $2.58,95 \%$ confidence interval (95\% CI) $1.22-5.48$ and OR 6.08, 95\% CI 2.06-17.92, respectively] after working $\geq 4$ years during nights, compared with men who had never worked nights. Working varied shift patterns did not show a significant impact on men's GHQ or self-reported anxiety/depression. In contrast, women's anxiety/depression and minor mental disorders (ie, GHQ-caseness) were adversely affected by working varied shifts for $2-3$ years (OR 2.58, 95\% CI $1.53-4.35$ ), and $\geq 4$ years (OR 4.17, 95\% CI 1.45-11.98) respectively, compared with women who had never worked varied shifts. In contrast, working nights was not associated with anxiety/depression among women. Although there was an association between undertaking $2-3$ years night work in women and reporting anxiety/ depression in both the unadjusted model (model 1) and when adjusting for all the socio-demographic characteristics (model 2), after mental health baseline was added to the model, there was no association between women undertaking night work and reporting anxiety/depression (model 3).

We also analyzed the interaction between gender and shift work using the combined sample of both men and women. We found that the interaction between working varied shift patterns and gender was significant, whereas the interaction between night work and gender was not.

\section{Discussion}

Undertaking shift work for $\geq 4$ years was associated with poor mental health for men and women, even after adjusting for the confounding factors. Therefore, shift work had a negative long term impact on mental health, which varied according to the duration of exposure, type of shift work, and gender. One possible mechanism was through (mental) stress, which has been found to be associated with shift work (35), and leading to emotional strain [ie, stress-and-strain model (36)]. Additionally, the level of distress due to shift work may be associated with the combination of changes in sleep patterns and domestic roles (37).

There are gender differences in the mental health effects of different types of shift work. Men's mental health was adversely affected by undertaking night shift work for $\geq 4$ years, while working varied shifts for $\geq 4$ years had a negative impact on women's mental health. Gender differences in family life roles and adaptation to shift work may provide explanatory frameworks for these different patterns of mental health impact. Moreover, men and women frequently work in different occupations which may also explain the gender difference in the impact of shift work on mental health. We, at least partially, adjusted for this by controlling for the number of years working in six different occupational categories in our analyses of the relationship between shift work and mental health.

Undertaking night work did not appear to be associated with adverse mental health consequences for women. This is an unexpected result, especially because many studies on nurses have had a different outcome (1, 5). However, some authors considered that nurses suffer from cumulative stress, due to their involvement with patients, as well as the stress of working nights, and consequently, their inferences from care work to other types of work and vice-versa may be problematic (38). In our study, women undertaking night work comprised a wide range of occupations, in addition to nursing. Additionally, women might be able to adapt more easily to night work, due to having more free time during the day, when they could perform their household chores and take care of children, and consequently, have less negative consequences on their mental health (25). Furthermore, the association between night work and mental health in women found in some studies may also be due to the lack of adjustment for baseline mental health in their models. This was supported by our results of an association between undertaking 2-3 years of night work and poor mental health in women in our unadjusted model 1 and when adjusted for confounders (ie, model 2). However, when we adjusted for baseline mental health in model 3 , there was no association between night work and poor mental health in women.

If there was a cumulative effect of night work on mental health, we would expect that workers with more years of shift work would have poorer mental health than those with fewer years (ie, dose-response effect). Our findings supported these dose-response relationships. Although there was a lack of association in some categories of 2-3 years shift work and mental health, our findings showed that the risk of poorer mental health significantly increased when workers were exposed to $\geq 4$ years of shift work. This is the reason why longitudinal studies on dose-response have used categories with more years of shift work, such as 6-10 years, $10-15$ years and $16-20$ years (26). If there had been bigger sample numbers undertaking 2-3 years or $\geq 4$ years shift work, the dose-response effects might have been more significant.

The possibility of comparing our results with other studies is limited, due to the scarcity of longitudinal studies on this subject, since studies have been primarily cross-sectional. Some researchers have acknowledged the importance of the duration of shift work when exam- 
ining the impact of shift work on mental health disorders (22) and therefore the absence of duration measures has been a limitation of many studies. Our study was longitudinal, used duration information, and was not performed on particular segments of population, thus it has extended results of the negative impact of shift work on mental health to the general working population.

Shift workers represent self-selected populations, and therefore, their characteristics in terms of their mental health status and socio-demographic status may be different compared to day workers. For example, being one of the strongest predictors of shift workers' mental health and anxiety/depression in 2005 in both genders, baseline mental health was a very important confounder when studying the impact of shift work on mental health. We adjusted for this effect, by including baseline mental health and baseline anxiety/depression in the analyses. Due to the importance of the work environment, we used the number of years working in different occupational categories as a proxy to reduce the confounding of our results by other work-related factors. The negative impact of shift work on mental health did not change, after adjusting for occupational categories. It is notable, that our findings contradicted Parkes' results (18) of altering the association between mental health and shift work, after controlling for occupation categories. However, her analysis was on a limited sample, thus her findings cannot be extrapolated to the general working population.

Analyses of secondary data have many advantages, but also some limitations. We lacked more detailed information on work environment factors, for example, which were suspected to cause some diseases and also associated with shift work (39). Moreover, detailed information on shift work was also lacking. Firstly, the number of consecutive nights undertaken in night work, which has an impact on circadian adjustment (40) was not available, but it would have been useful for a deeper analysis. Secondly, we did not have data on shift schedules and, therefore, we were not able to consider rotating shift work in this study. Instead, we focused on varied shifts where there is no usual pattern, which is assumed to lead to (more) difficulties in the adaptation of circadian rhythms and, consequently, health consequences. Additionally, the scarcity of longitudinal studies and/or shift work research on both men and women challenged our attempt to hypothesize about the reasons for gender differences in the impact of shift work on mental health. Our study was therefore, more exploratory than explanatory, bridging some gaps in the field.

It is essential to examine gender differences and control for self-selection effects when studying the impact of shift work on mental health. More information on the extent of the dose-response effect and the impact mechanism of shift work on mental health is needed from longitudinal research. Based on longitudinal data, our results showed that for men working nights and for women working varied shifts for $\geq 4$ years adversely affected mental health.

\section{Acknowledgements}

We acknowledge funding from the European Union Marie Curie Research Training Network "The biomedical and sociological effects of sleep restriction" (MCRTN-2004-512362). We are grateful to Elizabeth $M$ Thompson for her assistance in the early stages of this work and to Dr Robert Meadows for his very useful input regarding data management.

\section{References}

1. Suzuki K, Ohida T, Kaneita Y, Yokoyama E, Miyake T, Harano $\mathrm{S}$, et al. Mental health status, shift work, and occupational accidents among hospital nurses in Japan. J Occup Health. 2004;46(6):448-54.

2. Francesconi M, Bardasi E. The effect of non-standard employment on mental Health in Britain. Bonn (Germany): Institute for the Study of Labour (IZA); 2000. IZA Discussion Paper, no 232.

3. Poole CJM, Evans GR, Spurgeon A, Bridges KW. Effects of a change in shift work on health. Occup Med. 1992;42:193-9.

4. Costa G, Akerstedt T, Nachreiner F, Baltieri F, Carvalhais J, Folkard S, et al. Flexible working hours, health and wellbeing in Europe: some considerations from a SALTSA Project. Chronobiol Int. 2004;21(6):831-44.

5. Bohle P, Tilley A. The impact of night work on psychological well-being. Ergonomics. 1989;32(9):1089-99.

6. Martens MFJ, Nijhuis FJN, Van Boxtel MPJ, Knottnerus JA. Flexible work schedules and mental and physical health: a study of a working population with non-traditional working hours. J Organ Behav. 1999;20(1):35-46.

7. Frese M, Semmer N. Shiftwork, stress, and psychosomatic complaints: a comparison between workers in different shiftwork schedules, non-shiftworkers, and former shiftworkers. Ergonomics. 1986;29(1):99-114.

8. Gordon NP, Cleary PD, Parker CE, Czeisler CA. The prevalence and health impact of shiftwork. Am J Public Health. 1986;76(10):1225-8.

9. Geiger-Brown J, Muntaner C, Lipscomb J, Trinkoff A. Demanding work schedules and mental health in nursing assistants working in nursing homes. Work Stress. 2004;18(4):292-304.

10. Scott AJ, Monk TH, Brink LL. Shiftwork as a risk factor for depression: a Pilot Study. Int J Occup Environ Health. 1997;3 suppl 2:S2-S9. 
11. Bildt $\mathrm{C}$, Michelsen H. Gender differences in the effects from working conditions on mental health: a 4-year follow-up. Int Arch Occup Environ Health. 2002;75:252-8.

12. Waterhouse JM, Folkard S, Minors DS. Shiftwork, health and safety: an overview of the scientific literature 1978-1990. London: Her Majesty’s Stationery Office (HMSO); 1992. HSE Contract Research Report, no 31.

13. Kandolin I. Burnout of female and male nurses in shiftwork. Ergonomics. 1993;36(1-3):141-7.

14. Shen J, Botly LCP, Chung SA, Gibbs AL, Sabanadzovic S, Shapiro CM. Fatigue and shift work. J Sleep Res. 2006;15(1):1-5.

15. Rosa RR. Extended workshift and excessive fatigue. J Sleep Res. 1995;4 suppl 2:51-6.

16. Tepas DI, Barnes-Farrell JL, Bobko N, Fischer FM, IskraGolec I, Kaliterna L. The impact of night work on subjective reports of well-being: an exploratory study of health care workers from five nations. Rev Saúde Pública [Journal of Public Health]. 2004;38 suppl:26-31.

17. Skipper JK jr, Jung FD, Coffey LC. Nurses and shiftwork: effects on physical health and mental depression. J Adv Nurs. 1990;15(7):835-42.

18. Parkes KR. Shiftwork, job type, and the work environment as joint predictors of health-related outcomes. J Occup Health Psychol. 1999;4:256-68.

19. Harrington JM. Health effects of shift work and extended hours of work. Occup Environ Med. 2001;58:68-72.

20. European Foundation for the Improvement of Living and Working Conditions (Eurofound). Third European Working Conditions survey [Internet]. Dublin: Eurofound; 2007 [cited 2009 June 30]. Available from: http://www.eurofound.europa. eu/working/3wc/3wc18b.htm

21. Fujino Y, Mizoue T, Izumi H, Kumashiro M, Hasegawa T, Yoshimura T. Job stress and mental health among permanent night workers. J Occup Health. 2001;43:301-6.

22. Shields M. Shift work and health. Ottawa (Ontario): Statistics Canada; 2002. Health Reports, volume 13, no 4, p 11-33.

23. Muecke S. Effects of rotating night shifts: literature review. J Adv Nurs. 2005;50(4):433-9.

24. Hakola T, Härmä MI, Laitinen JT. Circadian adjustment of men and women to night work. Scand J Work Environ Health. 1996;22(2):133-8.

25. Barton J. Choosing to work at night: a moderating influence on individual tolerance to shiftwork. J Appl Psychol. 1994;79(3):449-54.

26. Knutsson A. Methodological aspects of shift-work research [review]. Chronobiol Int. 2004;21(6):1037-47.

27. Nabe-Nielsen K, Garde AH, Tüchsen F, Hogh A, Diderichsen
F. Cardiovascular risk factors and primary selection into shift work. Scand J Work Environ Health. 2008;34(3):206-12.

28. Kivimäki M, Virtanen $M$, Elovainio $M$, Väänänen $A$, Keltikangas-Järvinen L, Vahtera J. Prevalent cardiovascular disease, risk factors and selection out of shift work. Scand J Work Environ Health. 2006;32(3):204-8.

29. Andres AR. Determinants of self-reported mental health using the British household panel survey. J Ment Health Policy Econ. 2004;7(3):99-106.

30. Fryers T, Melzer D, Jenkins R. Social inequalities and the common mental disorders: a systematic review of the evidence. Soc Psychiatry Psychiatr Epidemiol. 2003;38(5):229-37.

31. Lynn P, editor. Quality profile: British Household Panel Survey [Internet]. Essex (United Kingdom): Institute for Social and Economic Research; 2006 [cited 2009 March 26]. Available from: http://www.iser.essex.ac.uk/files/bhps/qualityprofiles/BHPS-QP-01-03-06-v2.pdf

32. The Economic and Social Research Council (ESRC). The BHPS User Documentation and Questionnaires [Internet]. Colchester (United Kingdom): Institute for Social and Economic Research; c2007-c2009 [cited 2009 July 10]. Available from: http://www.iser.essex.ac.uk/survey/bhps/ documentation/pdf_versions/questionnaires/bhpsw10q.pdf

33. Goldberg, DP. The detection of psychiatric illness by questionnaire. London: Oxford University Press; 1972.

34. Cox BD, Blaxter M, Buckle ALJ, Fenner NP, Golding JF, Gore M, et al, editors. The health and lifestyle survey. London: Health Promotion Research Trust; 1987.

35. Estryn-Behar M, Kaminski M, Peigne E, Bonnet N, Vaichere E, Gozlan C, et al. Stress at work and mental health status among female hospital workers. Br J Ind Med. 1990;47(1):20-8.

36. Colquhoun WP, Rutenfranz J. Introduction. In: Colquhoun WP, Rutenfranz J, editors. Studies of shiftwork. London: Taylor \& Francis; 1980. p ix-xi.

37. Monk T. Coping with the stress of shift work. Work Stress. 1988;2 (2):169-72.

38. Poissonnet CM, Veron M. Health effects of work schedules in healthcare professions. J Clin Nurs. 2000;9:13-23.

39. Bøggild H, Burr H, Tüchsen F, Jeppesen HJ. Work environment of Danish shift and day workers. Scand J Work Environ Health. 2001;27(2):97-105.

40. Härmä M. Circadian adaptation to shift work: a review. In: Hornberger S, Knauth P, Costa G, Folkard S, editors. Shiftwork in the 21st century: challenges for research and practice. Frankfurt/M, Berlin, Bern, Brussels, New York, Oxford, Wien: Peter Lang; 2000. p 125-30. Arbeitswissenschaft in der betrieblichen Praxis, vol 17.

Received for publication: 29 December 2009 